\title{
El cambio en el sistema monetario de Japón y el peso mexicano en un expediente del Archivo Histórico Nacional de España de 1871
}

\section{The change in the Japanese monetary system and the Mexican peso in a file of the National Historical Archive of Spain of 1871}

DOI: 10.32870/mycp.v8i24.614

Pedro Damián Cano Borrego ${ }^{1}$

\begin{abstract}
Resumen
En el presente artículo se estudia la importante reforma monetaria japonesa del año 1871, por la que Japón se dotó de un circulante acorde con los modelos occidentales. Esta reforma, basada en el patrón oro, no podía ser ajena a las corrientes comerciales en vigor en Asia y el área del Pacífico, basadas en la moneda de plata y, muy especialmente, en el peso mexicano, por lo que conservó las emisiones de yenes batidos en metal argénteo para el comercio con las potencias extranjeras. Para este estudio se incorpora un documento conservado en el Archivo Histórico Nacional de Madrid, que pone de manifiesto la importancia que en el comercio tenía la moneda mexicana de plata.
\end{abstract}

Palabras clave: moneda, peso mexicano, política monetaria, comercio asiático, Japón.

\begin{abstract}
This article examines the important Japanese monetary reform of the year 1871, for which Japan was endowed with a currency according to Western models. This reform, based on the gold standard, could not be alien to the current trade flows in Asia and the Pacific area, based on the silver coin and especially in the Mexican peso, so it retained the emissions of yen milled in silver for the commerce with the foreign powers. This study incorporates a document preserved in the Archivo Histórico Nacional of Madrid, which shows the importance that in the trade had the Mexican currency of silver.
\end{abstract}

Keywords: currency, Mexican peso, monetary policy, Asian trade, Japan.

Artículo recibido el 29 de enero de 2019 y dictaminado el 20 de marzo de 2019.

1. Investigador independiente. Doctor en Historia y Arqueología, Universidad Complutense de Madrid, España. ORCID: http://orcid.org/0000-0002-2806-4327. Correo electrónico: pietroyanaky@ telefonica.net 
Los europeos introdujeron en los mercados asiáticos miles de toneladas de plata entre mediados del siglo XVI y mediados del siglo XVII, que se unieron a las ingentes cantidades del mismo metal que se importaron a China desde Japón. A pesar de ello, entre 1550 y 1650 China exportó oro a Europa, a Japón y a la Nueva España, dado que el poder adquisitivo de la plata duplicaba en China al de cualquier otro punto del planeta, mientras que el del oro en Europa era mucho mayor. Para Flynn y Giráldez (2000) el comercio de moneda española acuñada se entiende solamente cuando se sitúa en un contexto global, en el que los principales productores de plata eran los reinos de las Indias españolas, especialmente la Nueva España y Japón, no Europa, y China era su principal mercado de destino. Los comerciantes europeos eran, según estos autores, meros intermediarios en el comercio global de los metales preciosos, tanto los portugueses como los holandeses, ingleses, franceses o daneses, así como los españoles directamente a través del Galeón de Manila (Cano, 2018).

En Japón también abundaba el oro, especialmente en el territorio controlado por el shogunato Tokugawa (1603-1867), y los daimyo de Kiushu se beneficiaron de la vecindad de ricas minas de plata. La plata procedente de Wami, Tajima y Sado se extraía y depuraba utilizando un método conocido como nan-batuk o bárbaro, posiblemente aprendido de los portugueses (Valdés, 2003). El mismo shogun solicitó que se enviasen desde Nueva España 50 mineros para compartir sus conocimientos y técnicas en la explotación de la plata (Barrón, 1992, p. 68). La apertura de la ruta comercial Manila-Usuki en 1602 redujo el número de barcos japoneses autorizados para comerciar con el archipiélago filipino y retrajo la exportación de plata japonesa a Manila, que hacía disminuir el valor de los reales de a ocho pesos españoles e incrementaba el precio de la seda china.

Las relaciones comerciales con los españoles continuaron hasta que en 1624 se rompieran las relaciones diplomáticas con Filipinas, y tras la batalla de Shimabara en 1639 se cerraron los puertos japoneses al comercio con las Coronas ibéricas (Iaccarino, 2013, pp. 141-142). Si bien Japón fue en la Edad Moderna un país cerrado al comercio exterior, con producción propia de plata y con su propio sistema monetario, el peso español recibía una valoración de 70 a 74 candareens, de las que 100 equivalían a un tale de plata (Eckfeldt \& du Bois, 1842, p. 74).

El sistema monetario japonés en la Edad Moderna, instaurado por el shogunato Tokugawa, estaba compuesto por piezas de oro, plata y cobre; si bien el nuevo numerario de cobre tardó en acuñarse — dado que había en circulación 
gran número de monedas chinas-, posteriormente se batió en grandes cantidades. Este numerario de cobre, conocido como Kanei Tsuho o moneda de Kanei, se acuñó durante tres siglos, muchas veces por comerciantes habilitados. Hubo asimismo otras emisiones en este metal, como la Kyoho Tsuho desde 1715, o las piezas ovaladas de cien mon, cien monedas de cobre, de facial. En 1588 se acuñó el tensho oban o moneda de plata. Junto a ello, se emitieron desde 1600 billetes de banco, los Yamada Hagaki y otros, por los señores feudales, por los propietarios de minas o en diversas localidades (Seco, 2010).

\section{El peso mexicano en los mercados asiáticos}

Tanto en el área del Pacífico como en el Índico, la moneda de plata española circuló ampliamente, siendo considerada habitualmente como una mercancía por su alto contenido en metal noble. Esto permitía mantener para el comercio un parámetro monetario para la comparación de las demás monedas, evitando con ello las fluctuaciones regionales y las diferencias entre sus apreciaciones (Valdés, 2003). Por lo tanto los comerciantes orientales como los occidentales obtenían seguridad en sus transacciones. A pesar de la presencia de otras monedas, la mayor parte del numerario de plata presente en China se componía de moneda española de plata de todos los faciales (Cipolla, 1996, p. 101).

Los pesos españoles comenzaron a ser familiares en los puertos de Cantón, Higpo y Amoy desde 1571, por su relación comercial con las Filipinas. Fue el comercio con los españoles de Manila y con los portugueses de Goa y Malaca el que familiarizó a los chinos con la moneda que sería dominante en el comercio en las siguientes tres centurias (Chalmers, 1893, p. 371). China absorbió una parte importantísima de la producción de plata, estimulada por su demanda interna, y muy especialmente durante el siglo XVIII, cuando triplicó su población. Con ello se consiguió que la masiva inyección del nuevo numerario en los mercados mundiales no se tradujese en un desplome de su precio, lo que resultó crucial para sostener las bases financieras del Imperio español (Gunder, 1998, p. 246).

La edad de oro de la plata acuñada en las Indias fue el siglo XVIII. Durante esa centuria todos los comerciantes y todas las compañías que operaban en India, Indochina y China utilizaban este numerario. Los más comunes fueron los reales de a ocho, los de tipo columnario, denominados shuang zhu yang, y los posteriores a la reforma de Carlos III, de busto y escudo en reverso flanqueado por las columnas de Hércules. Estos últimos, batidos en los 
reinados de Carlos III y posteriormente de Carlos IV, eran los más comunes; los primeros se denominaban pesos de tres caracteres gong, por la similitud del signo gong con el numeral I romano. También se encontraban, aunque en menor medida, los acuñados en tiempos de Felipe V y de Fernando VI. La mayor parte del numerario procedía de la ceca de México, y en menor medida de Potosí y de Lima.

Como pone de manifiesto Bonialian (2012), los principales flujos comerciales por los que circularon las mercancías asiáticas estuvieron controlados al menos hasta la primera mitad del siglo XVIII por el Consulado de la ciudad de México y por el de Lima. Los principales flujos comerciales fueron según este autor, en primer lugar la Nao de la China o Galeón de Manila, en segundo lugar el comercio triangular entre Europa, Perú y China, conocido como el "comercio francés", y las conexiones clandestinas entre los comerciantes de los virreinatos meridional y septentrional, con una notable intensidad entre los años 1675 a 1740.

La moneda acuñada en la ceca de México bajo el gobierno español siguió siendo, tras su independencia, utilizada en China (figura 1) como alternativa a los sycee locales. Este numerario, conocido como Ban Yang, era el comúnmente aceptado a mediados del siglo XIX (Te K'un, 1961). Los pesos batidos por la República Mexicana circulaban ya desde 1840, pero en Shangai se vendían con descuento hasta el año 1860 (McMaster, 1959, p. 390). Tras el estallido de la gran revuelta Taiping, la escasez monetaria hizo que en el año 1856 la Asociación de Banqueros de Shangai aprobase aceptar los yin yang, literalmente dólares del águila, acuñados por México independiente, una aceptación que posteriormente se amplió a los principales centros comerciales chinos (Cano, 2010, p. 649).

El peso mexicano (figura 2) porta en su anverso la leyenda RePÚBlicA MeXICANA y la fecha de emisión, y como motivos el escudo nacional: un águila sosteniendo una serpiente en su pico apoyada sobre un cactus, bajo el cual se sitúa una corona abierta de hojas de laurel y roble. En su reverso lleva la leyenda UN PESO, la marca de ceca y la ley, 902.7, y como motivos un gorro frigio radiante con la leyenda LIBERTAD sobre una espada cruzada y una balanza, de la que cuelga un pergamino con la leyenda LEY. 
Figura 1

Mapa de China y Japón en 1881

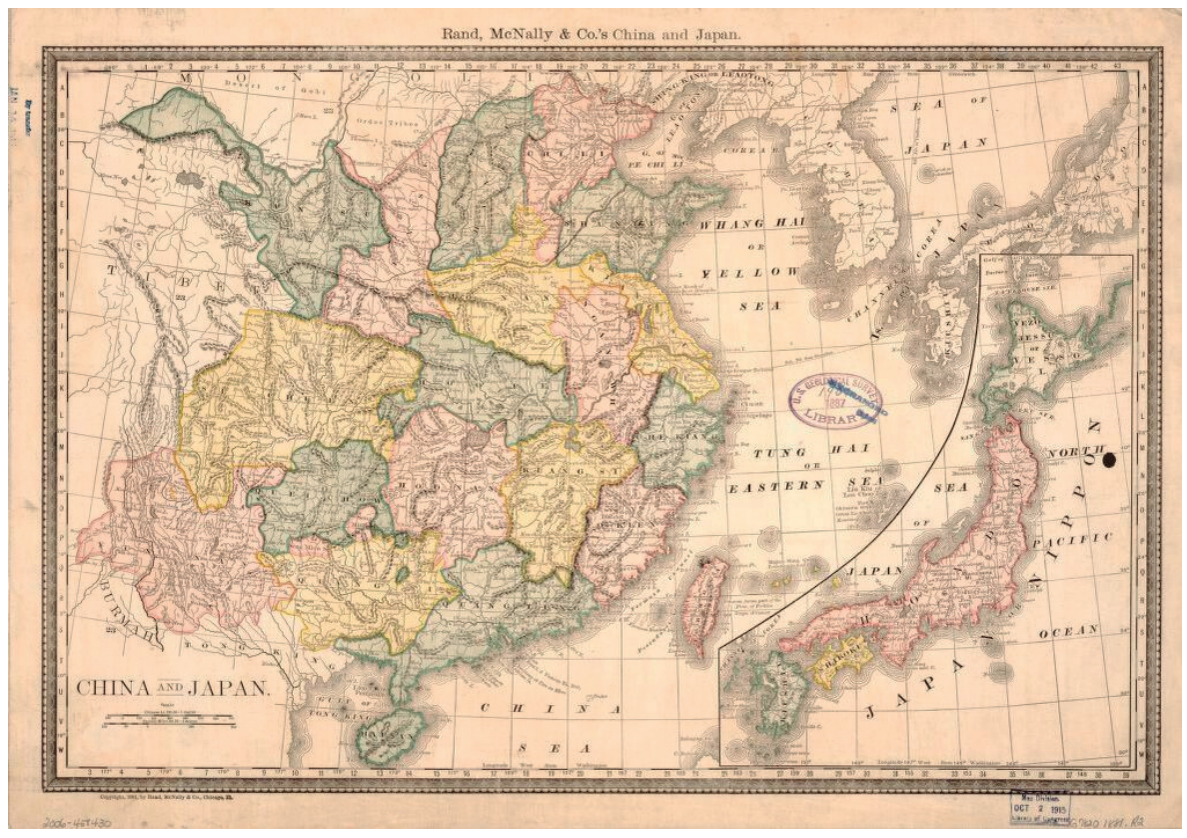

Fuente: Library of Congress Geography and Map Division Washington, D. C. G7820 (1881).

Por el Tratado de Kanagawa, en 1858, se impuso el Mexican dollar, peso mexicano o yogin como una medida para dominar aún más a Japón, puesto que su valor por peso y contenido de metal era superior a la plata japonesa (Valdés, 2003). En febrero de 1868 el Gobierno japonés reguló que el peso mexicano debía ser aceptado a una estimación fijada de tres de las nuevas monedas japonesas de plata, bu, por peso (Motoyama \& Yokoyama, 1994, p. 2).

En abril de ese mismo año el Gobierno japonés compró la maquinaria de la Casa de Moneda de Hong Kong, que ardió antes de ser remitida, por lo que se importó nueva maquinaria directamente desde el Reino Unido. El director de esta ceca, el mayor William Kinder, fue nombrado director de la Casa de Moneda de Japón, y se contrató a nueve ingenieros europeos. Por la Nueva Ley Monetaria de 1870 se adoptó la moneda de oro, mientras que para los pagos para el comercio exterior en los puertos habilitados se acuñó un yen de plata (Motoyama \& Yokoyama, 1994, p. 2). 


\section{Figura 2}

Peso mexicano de 1870
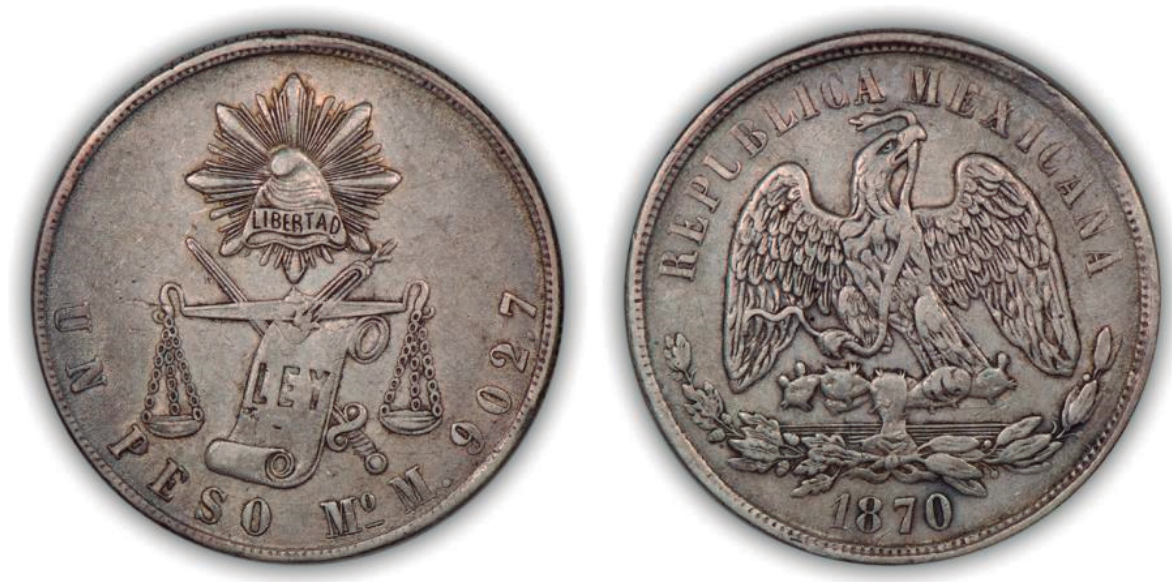

Fuente: VCoins The Online Coin Show (2018).

Los cargamentos de pesos mexicanos enviados directamente a Asia nollegaron a tener un volumen considerable hasta los años 1860-1870, época cuando se iniciaron las operaciones a través de San Francisco. El comercio de Japón con Estados Unidos experimentó según McMaster (1959, p. 377) un incremento de ocho millones y medio de pesos entre 1862 y 1885 . En 1859, de los 30 millones en metálico que pasaron a través del puerto de Hong Kong, la mayor parte era plata mexicana. El mismo autor recoge que una empresa relativamente pequeña, la Jardine Matheson Company de Yokohama, tenía hacia 1860-1870 entre cien mil y un millón de pesos de plata disponibles para sus compras de té y seda, y que no era extraordinario que un único vapor procedente de Shangai llevase como carga con destino a las compañías establecidas en Japón un montante de medio millón de pesos. 


\section{Figura 3}

Yen de plata del año 3 de la Era Meiji, 1870
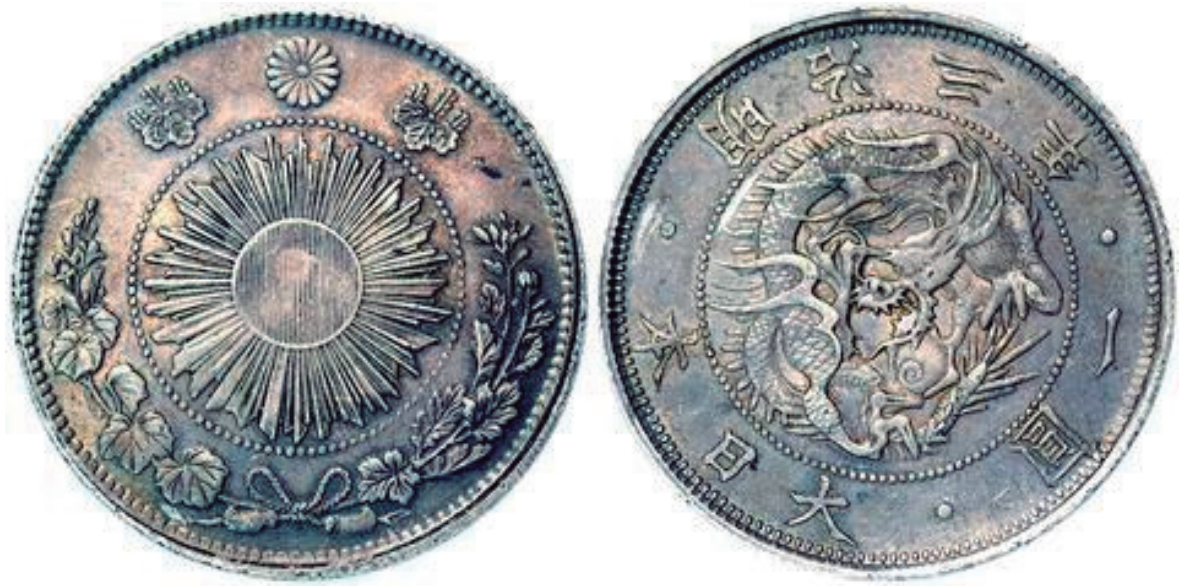

Fuente: Shopify Coins (2018).

\section{La reforma monetaria japonesa}

Entre las importantes reformas llevadas a cabo por el emperador Mutsuhito (1852-1912), se decretó la abolición de las antiguas monedas de la época Tokugawa, en un nuevo sistema monetario basado en el yen como unidad, y sus divisores el sen y el rin (figura 3). Seco (2010, pp. 171-172) nos informa cómo el término yen se pronuncia en japonés en, y su grafía occidental se relaciona con una forma de pronunciación de la "e" inicial en japonés recogida en los textos españoles y portugueses del siglo XVI, que posteriormente desapareció en el siglo XVIII.

Según Angot (1876, p. 74), la inteligente política de los ministros Sanja e Iwakuova hizo que las modificaciones económicas mejorasen el estado del comercio, siendo la primera de ellas el de su sistema monetario, adoptándose el yen de plata de 26.956 gramos de $\% / 10$ de plata pura, como el dólar estadounidense, que recibía una estimación de cinco francos y 39 céntimos. Este yen se dividía en cien sen y mil rin, y tanto los divisores como los múltiplos batidos en oro se acuñaron con profusión en la casa de moneda de Osaka.

Este nuevo sistema monetario, basado en el yen, literalmente objeto redondo, fue adoptado oficialmente por una ley de 10 de mayo de 1871 (Andrew, 1904, p. 345), y sus unidades monetarias fueron introducidas gradualmente a partir 
de julio de ese mismo año. Con anterioridad, en el año 1870 se habían acuñado monedas de oro de 1, 2, 5, 10 y 20 yen, así como moneda de plata de 1 yen y 5 , 10,20 y 50 sen. Se adoptó por esta norma un sistema decimal, y se comenzaron este mismo año las emisiones de un yen de oro (figura 4). En 1873, en plena devaluación monetaria, se acunaron monedas de cobre de 1 rin y $1 / 2,1$ y 2 sen.

\section{Figura 4}

Yen de oro del año 3 de la Era Meiji, 1871
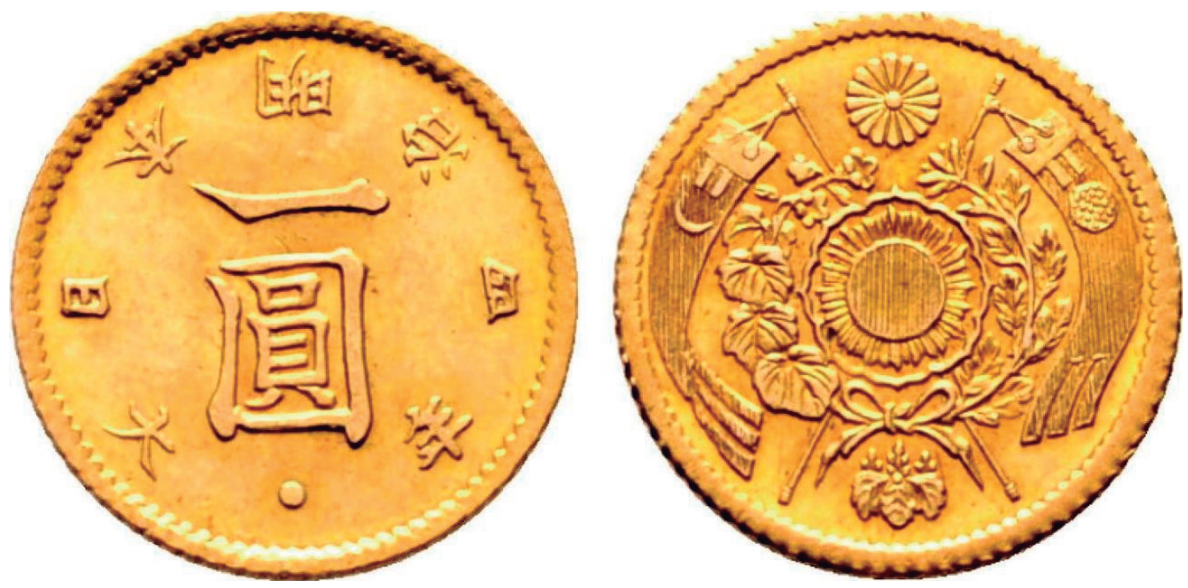

Fuente: Ma-Shops (2018).

Por esta reforma monetaria se fijó la paridad del yen de oro con el de plata en 16.01 a 1, una valoración algo menor que la de los mercados internacionales (Motoyama \& Yokoyama, 1994, p. 2). Debido a ello, y a la depreciación de la plata en Occidente, se estima que un $51.3 \%$ de la moneda áurea acuñada en Japón fue sacada del país desde ese año hasta 1877.

Estas nuevas monedas se apartaron de los modelos clásicos japoneses, acercándose a los tipos occidentales, si bien tanto en su escritura como en su iconografía se relacionaban con la tradición japonesa. Se utilizó la leyenda Dai Nippon, Gran Japón, y como motivos las flores de paulonia, el sol naciente o el dragón. La paulonia es una flor utilizada como emblema del Gobierno nipón, como el crisantemo se relaciona con la Casa Imperial.

En 1897 se desmonetizó el circulante de un yen de plata de valor facial y se redujo el tamaño del áureo a la mitad, cesando la producción de moneda argéntea en 1938. En cuanto a los billetes de banco, las primeras emisiones 
con tipología occidental y valor en todo el territorio fueron impresos por una compañía alemana, hasta que en 1882 el Banco Nacional de Japón se hizo cargo de las emisiones (Seco, 2010, p. 172).

\section{Las relaciones hispano-japonesas en 1871}

El influjo liberal del Sexenio Revolucionario en España tuvo eco en el archipiélago filipino (figura 5), con las reformas impulsadas por Manuel Becerra y Segismundo Moret desde el Ministerio de Ultramar. Becerra liberalizó el comercio exterior en 1869, suprimiendo el derecho diferencial de la bandera. Asimismo, se creó una Comisión Consultiva de Reformas de Filipinas y se presentó al Congreso la Ley de Presupuestos de Ultramar. A pesar del recelo de las órdenes religiosas, con gran poder fáctico en las islas, se concedió la libertad religiosa a los residentes extranjeros.

\section{Figura 5}

Carta de España de Bachiller con todas sus posesiones de ultramar e islas adyacentes 1858. Fragmento: Islas Marianas, Palaos y Carolinas (Oceanía)

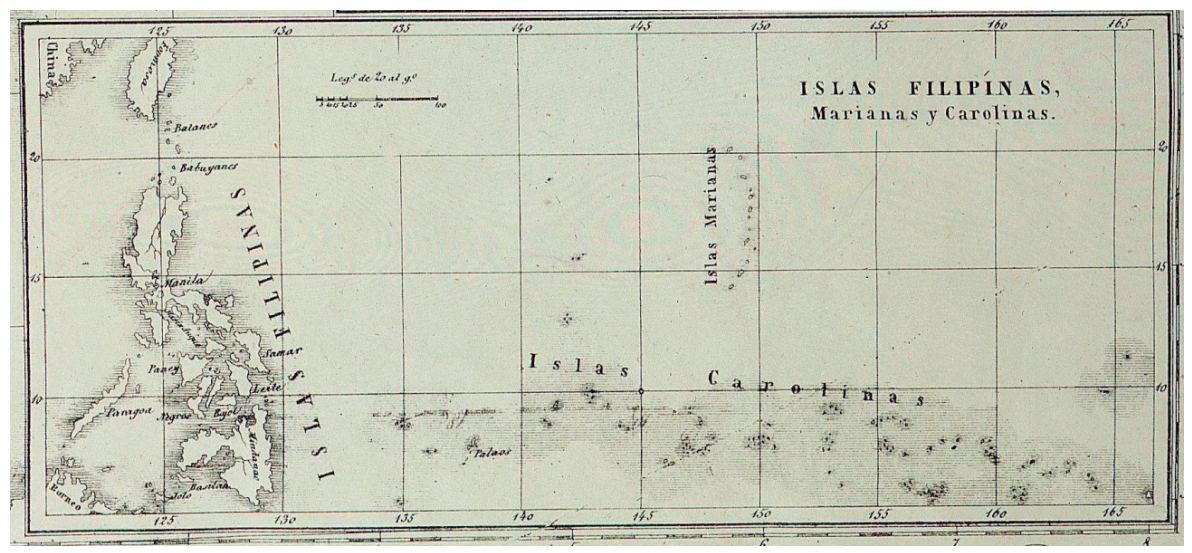

Fuente: Biblioteca Nacional de España, Madrid (1858).

Por su parte, Moret aprobó entre agosto y diciembre de 1870 nuevos aranceles para favorecer la entrada de productos para el desarrollo de la economía, y la sociedad filipina fomentó las relaciones internas entre las distintas islas e impulsó las comunicaciones con la Península a través del Canal de Suez. Estas 
medidas reformistas fueron posteriormente abandonadas tras la restauración borbónica, suspendiéndose las reformas y restableciendo la legislación anterior (Elizalde, 2004, pp. 360-361).

Desde el mismo año 1858 hubo peticiones para que España se incorporase al sistema de los "tratados desiguales" vigente en Japón, y desde el año 1861 los gobernadores generales de las islas Filipinas elevaron peticiones de que se firmara un acuerdo a petición de los comerciantes de Manila, con base en los lazos de vecindad, que en el pasado habían sido estrechos, para el desarrollo del comercio del archipiélago. Finalmente, a comienzos de 1868 se nombró al ministro plenipotenciario en Pekín, José Heriberto García de Quevedo, como enviado especial. La firma del Tratado de amistad, comercio y navegación hispano-japonés de 12 de noviembre de $1868^{2}$ fue uno de los primeros acuerdos rubricados por el nuevo Gobierno Meiji (Martínez, 2015).

En el artículo décimo de dicho Tratado se establecía lo siguiente, en referencia a la moneda:

Todas las monedas extranjeras tendrán curso en el Japón, y pasarán por su peso correspondiente en moneda japonesa del mismo metal. Tanto los españoles como los japoneses usarán libremente de las monedas extranjeras o japonesas en sus pagos mutuos.

Las monedas de todas clases, excepto la de cobre japonesa, podrá exportarse del Japón, así como también el oro y la plata extranjeros no acuñados.

El Gobierno japonés se obliga a cambiar en moneda del país de igual valor intrínseco, menos el costo de la acuñación en los puntos designados para el cambio, todas las monedas extranjeras de ley o de vellón, y las barras de oro o de plata que en cualquier tiempo le presenten al efecto los extranjeros o japoneses. El costo de la acuñación se fijará ulteriormente por acuerdo de las Altas Partes contratantes.

Pocos años antes, en 1857, se había establecido la Casa de Moneda de Manila con el fin de dotar de numerario a las posesiones españolas de Filipinas y a los archipiélagos de la Micronesia española (Marianas, Carolinas y Marquesas). Aunque por Orden de 1861 se había decretado la retirada de la circulación de la moneda de plata batida en las cecas hispanoamericanas y su sustitución por la acuñada en esta nueva ceca, el peso mexicano, al igual que sucedía en todos los países y colonias de Asia y Oceanía, se había convertido en la moneda del

2. Su ratificación por parte del Gobierno español puede consultarse en la Gaceta de Madrid, año ccx, núm. 35, martes 31 de enero de 1871, p. 257. 
comercio, por lo que en 1876 se autorizó su circulación, en paridad con las emisiones de la ceca manilense (Cano, 2016, p. 119).

\section{El expediente sobre el cambio del sistema monetario de Japón}

El expediente ${ }^{3}$ estudiado consta de 18 páginas. En la primera de ellas se informa que el mismo se llevó por el Ministerio de Ultramar, en su sección de Hacienda y en el Negociado de Administración, y su asunto era "Sobre el proyecto del Gobierno Japonés con la acuñación de moneda en aquel país”. En la siguiente página encontramos el traslado del mismo:

El Ilmo. Sr. Subsecretario del Ministerio de Estado, con fecha 26 Setiembre de 1871, traslada un Despacho del Encargado de negocios de España en el Japón sobre el proyecto presentado por el Gobierno japonés para arreglar la acuñación de la nueva moneda, y acompaña copias nos. 1 y 2 de las comunicaciones que sobre este asunto han mediado entre el Gobierno Japonés y nuestro representante en aquel país.

Madrid, 12 Octubre 1871.

Rafael López Guijarro.

En las siguientes páginas encontramos los traslados que del mismo se hicieron a otros ministerios:

El Negociado cree procedente se transmita al Gobernador Superior Civil de las Islas Filipinas de comunicación del Ministerio de Estado que queda extractada, con copia de los despachos que la acompañan a los efectos que haya lugar en aquel archipiélago, encargándole que si de la resolución del Gobierno Japonés a que se refieren aquellos documentos, se notase algún perjuicio dimanado para el comercio del otro archipiélago de conocimiento a este Ministerio en comunicación razonada, para entablar la gestión conducente a su remedio.

Esto no obstante, cree el que suscribe que el conocimiento de este asunto corresponde a la Sección del Gobierno y Documento, como que se trata de una cuestión de comercio más que de Hacienda, y por tanto, parece que sería procedente que por aquella se procediera una resolución, como competente en el particular

E. de Castro y Serrano

21 de noviembre 1871

3. Archivo Histórico Nacional de España, Ultramar, 473, exp. 8. 
Sección de Gobierno y documento

Negociado de Fomento

Examinados los despachos diplomáticos del Ministro Español residente como representante nuestro en el Japón, resulta del Anejo $1^{\circ}$ al Despacho núm. 79 de 27 de junio, que el Gobierno japonés ha legislado respecto a la acuñación suplementaria del oro, la plata y cobre, introduciendo variaciones en la moneda de aquella nación, que se detallan muy especialmente en dicha comunicación. El Anejo al Despacho núm. 79 de 14 de julio es la contestación de nuestro encargado de Negocios a los Ministros de relaciones exteriores japoneses, haciendo observaciones a los Reglamentos que el Gobierno del Mikado se propone establecer en la casa de moneda, observaciones referentes a cuanto convenga a los intereses de los españoles, y a la estricta observación de lo estipulado en los tratados, dada la variación de la moneda en el imperio del Japón.

El oficial que informa, cree deben trasladarse íntegros ambos despachos (Anejos) al G. S. C. de las Islas Filipinas, a fin de que reconozcan nuestros nacionales, en aquel Archipiélago, por exigirlo así las transacciones comerciales entre España y el Japón, las variaciones que el Gobierno del Mikado introduzca en la moneda de una nación tan inmediata a las citadas Islas Filipinas.

Madrid 23 de Noviembre de 1871. Prieto y Prieto.

El Ministro de Estado da cuenta de un proyecto del Gobierno japonés en la acuñación de moneda en aquel país.

[...]

El Negociado, que se traslada al G. S. C. de Filipinas a fin de que se tenga conocimiento en aquel Archipiélago.

El 30 de noviembre de ese mismo año en una nota se muestra la satisfacción y conformidad. Finalmente, se reproducen la comunicación del encargado de negocios de España en Japón y los anexos que contienen la información que los representantes españoles recibieron de las autoridades japonesas y remitieron a España: 
$473 / 8 n^{\circ} 2$

Ministerio de Estado

Sección de comercio

11-8-71

Excmo. Sr.,

El Encargado de Negocios de España en el Japón en su Despacho nº 79 de 22 de Julio último dice a este Ministerio lo siguiente:

"He tenido el honor de hablar a V. E. incidentalmente y a la ligera en mi Despacho $\mathrm{n}^{\circ} 76$ fecha 10 del actual del proyecto presentado por el Gobierno japonés para arreglar, sin perjuicio de los extranjeros la acuñación de la nueva moneda. Para V. E. este al cabo de este importante asunto incluyo adjunta copia $\mathrm{n}^{\circ} 1$ del despacho sobre el particular que me dirigió el Gabinete de Yedo y copia $\mathrm{n}^{\circ} 2$ de la respuesta que le he dado de acuerdo con mis colegas. Las tablas monetarias no las envío porque no hacen el caso para el fondo de la cuestión y sus interés es puramente local.

De Real orden comunicada por el Sr. Ministro de Estado lo traslado a V. E. con inclusión de los documentos citados, para su conocimiento y efectos oportunos. Dios guarde a V. E. muchos años.

Madrid 26 de Setiembre de 1871.

El Subsecretario

Señor Ministro de Ultramar

$473 / 8 n^{\circ} 3$

Ministerio de Estado

Sección de Comercio

Anejo $1^{\circ}$ al Despacho $n^{\circ} 79$

Tokei el 10 del quinto mes del cuarto año Meiji (27 de Junio 1871)

Excelencia: El Gobierno japonés comunicó con V. E. anteriormente respecto a la acuñación suplementaria del oro, la plata y cobre, que había decidido llevar a efecto y os informo del marco, pureza, peso y valor relativo que tendría dicha acuñación. Además fue celebrada la inauguración de la casa de moneda que presenció V. E como testigo. Más habiendo tomado en consideración el sistema de acuñación de países de Europa y América, estudiado los principios que en ella rigen y habiendo consultado con personas experimentadas en el asunto, el Gobierno japonés ha sacado en conclusión que sirviendo el oro de tipo en muchos países, la plata es tan solo una moneda subsidiaria, lo cual se desprende de las cualidades inherentes a ambos metales. Creemos también que sería en extremo beneficioso a las Naciones las relaciones de tráfico internacional si se adoptara para la unificación con los marcos o etalons. Hemos oído que hace algunos años 
se celebró en París un Congreso monetario con objeto de establecer un nuevo sistema de acuñación cuya unidad o marco sería común a varias naciones, lo cual, según no ignoráis, es el constante deseo de los negociantes de todos los países. Así pues, opinando que sería lo más acertado el establecer el marco, finura y peso de nuestros cuños con la mayor semejanza posible al marco, finura y peso de varias naciones comerciales, hemos decidido acuñar las siguientes monedas de oro, a saber: Primero (20) veinte Yen, que contendrán treinta (30) gramos de oro puro y cuyo tipo de peso será treinta y tres y un tercio (33 1/3) gramos; el tipo de finura será de nueve décimos (9/10). Segundo: diez Yen. Tercero cinco Yen. Cuarto dos Yen. Quinto un Yen. El valor proporcional de estas monedas y su peso correspondiente a las diferentes denominaciones será según muestra la tabla adjunta que trata de la moneda de oro. Por la misma razón es de desear la abolición de la moneda de plata de un yen que antes se había adoptado como tipo legal. Sin embargo a fin de facilitar las transacciones en los puertos abiertos, se acuñará la moneda de plata de un yen para aquellas personas que lleven la plata en barras a la casa de la moneda. Dicha moneda de plata de un yen será también considerada como de curso legal, más únicamente en los puertos abiertos a los extranjeros, en donde será equiparable al peso mejicano y como este admitido en la circulación. También el peso mejicano será admitido en las transacciones como hasta ahora lo ha sido. Cada una de las cinco citadas especies de moneda de oro, entre las cuales figura como tipo o étalon la de oro de un yen, tendrán curso legal y por consiguiente habrán de ser admitidas en todos los pagos, cualesquiera que sea su importancia. Las monedas de plata, a contar de la de cincuenta céntimos inclusive, a saber: 50 cent $=20$ cent 10 cent $=5$ cent serán las monedas subsidiarias cuyo tipo y finura continuarán en la forma que hemos comunicado a V. E. Más en cuanto a un peso y a la cantidad legal que deba entrar en todo pago, se ha hecho una alteración que hallareis en el Reglamento de la casa de la moneda y en la tabla aneja de las monedas de oro y plata. Dado el caso de que pensara el Gobierno japonés modificar alguno de los presentes reglamentos tomará preferentemente en consideración al hacerlo. La conveniencia y los intereses del comercio indígena y del extranjero. Con respeto V.

Firmado Sawa Nobuyoshi. Terashima Munenori, Ministros de Negocios Extranjeros. Es copia conforme. El Secretario de la Legación, Emilio de Ojeda. Es copia conforme.

El subsecretario Nobuyoshi Sawa ostentó el cargo de ministro de Asuntos Exteriores de Japón entre el 4 de mayo de 1868 y el 20 de junio de 1869. El conde Terashima Munemori ostentó el mismo cargo a partir de 1873 . Munemori intentó sin éxito renegociar el tratado desigual firmado con Estados Unidos, si bien la oposición británica llevó a que no se llevase a buen término. 
El expediente continúa con una copia de una carta remitida por Tiburcio Rodríguez desde Yokohama:

\section{$473 / 8 n^{\circ} 4$}

Ministerio de Estado

Sección de Comercio

Anejo $2^{\circ}$ al Despacho $n^{\circ} 79$

Yokohama, 14 de julio de 1871

Excelencias: He recibido la carta oficial que VVEE me han hecho el honor de dirigirme con fecha 25 de Junio, transmitiéndome los reglamentos que el Gobierno del Mikado se propone establecer en la casa de moneda de Osaka así como los cuadros indicativos del peso, nombre y valor de las diferentes nuevas monedas. Mis colegas y yo hemos examinado dichos documentos con la más detenida atención, y no puedo ocultar a VVEE que el sistema monetario puesto en vigor por el Gobierno no parece corresponder en opinión nuestra a las esperanzas anteriormente concebidas. Sin entrar a discutir el mérito del marco de oro comparado con el marco de plata, no podemos menos de expresar nuestro pesar al ver que el departamento de Hacienda abandona el proyecto primitivo que, dando un justo valor al hecho de las relaciones directas del Japón con países donde no existe la moneda de oro, parecía estar más adecuada y más acomodada a los prudentes preceptos de la economía política. Cierto es que VVEE anuncian la emisión de un Yen de plata el cual tendrá en los puertos abiertos el mismo curso que el peso mejicano. Pero no sería cuerdo dar una grande importancia a esta derogación del sistema general cuando según todas las probabilidades el comercio extranjero ninguna razón tendrá para acudir a la casa de moneda en demanda de acuñación de Yenes de plata supuesto que el peso mejicano lleva consigo todas las ventajas de esta especie numeraria sin el inconveniente de dos por ciento del pago. Así que, en realidad es muy de temer que la nueva moneda de plata, en vez de facilitar las transacciones comerciales sea para ellas una causa de confusión. Podría hacerse una crítica igualmente justificada de muchas otras disposiciones del Reglamento, en particular de la contenida en el último párrafo del artículo $4^{\circ}$ donde se establece el valor relativo del oro y de la plata y de la que fija (último párrafo del artículo $4^{\circ}$ del suplemento) la relación entre Yen de oro y el Yen de plata. Pero según ha sido declarado en las últimas conferencias, los representantes extranjeros reconocen que estas cuestiones son de la exclusiva competencia del Gobierno japonés, y si intervienen en las medidas adoptadas por el Ministerio de Hacienda, es con el objeto de amparar los intereses de sus nacionales. En consecuencia me limito de acuerdo con mis colegas, a hacer hoy las más completas reservas tocante a los derechos de los súbditos españoles y a la estricta observación de lo estipulado en los tratados si más adelante, al ser puesto en práctica el nuevo reglamento, se viese que contiene disposiciones ca- 
paces de menoscabar a dichos derechos o dichas estipulaciones, me veré obligado a oponerme a su aplicación a lo concerniente a mis nacionales.

Firmado: Tiburcio Rodríguez y Muñoz.

Es copia conforme.

El Subsecretario Tiburcio Rodríguez y Muñoz había sido enviado como encargado de Negocios y máximo representante español a Japón en 1869, al abrir en este país su legación, y se mantuvo en el puesto hasta 1873.

Finalmente, en fecha 30 de noviembre de 1871 se remitió por el Ministerio de Ultramar, sección $1^{\circ}$, Negociado 24, al Gobernador Superior Civil de Filipinas copia de las comunicaciones, con lo que se cierra el expediente:

Excmo. Señor,

De Real Orden comunicada por el Sr. Ministro de Ultramar, tengo el honor de remitir a VE copia de dos comunicaciones que han mediado entre el Gobierno japonés y el representante de España en el Japón, acerca de las alteraciones hechas en el sistema monetario de aquel país, a fin de que VE decida disponer la inserción de dichos documentos en los periódicos oficiales de esa provincia para conocimiento del público.

El Subsecretario.

\section{Conclusión}

En 1843 Dupont (1843, pp. 178-179) afirmaba que el peso, el real de a ocho, era todavía a mediados del siglo xIx la moneda más universal, y había servido durante siglos para las grandes transacciones comerciales del mundo marítimo. Los pueblos de Oriente reconocieron durante siglos en las armas del rey de España la garantía de un peso constante y un contenido en plata fidedigno, teniendo una gran repugnancia en aceptar en su lugar monedas de nuevo cuño, que no les ofrecían un grado de seguridad bien conocido por una larga experiencia. En su trabajo sobre la historia de la moneda en las colonias británicas de 1893, Chalmers (1893, p. V) realizó una recopilación de la historia de los viejos pesos fuertes españoles o piezas de a ocho, así como de su representación mexicana coetánea, el peso, que estimaba era la más completa de todas las referidas, según sus palabras, a esta moneda universal durante tres siglos (Cano, 2018). 
México continuó exportando pesos de plata a China hasta que en el año 1904 adoptó el patrón oro y prohibió la exportación de su moneda de plata. Aun así, y por el hecho de que se había desarrollado el sistema bancario y los pagos en papel, McMaster recoge que los pesos seguían gozando de "un uso mucho más general entre el populacho" (1959, p. 378). Otras monedas que circularon en los mercados asiáticos con mayor o menor amplitud fueron el British Trade Dollar, el American Trade Dollar y el yen japonés.

Entre 1864 y 1866 los ingleses habían acuñado en Hong Kong una copia del peso mexicano, pero a los chinos no les gustó el dibujo que llevaba grabado, y, cuando ya se habían acuñado dos millones, se vio que el experimento había sido un fracaso (figura 6). Desde 1895 los británicos emitieron más de 150 millones de monedas iguales a las mexicanas en un periodo de ocho años (McMaster, 1959, p. 393).

\section{Figura 6}

\section{American Trade Dollar de 1872}
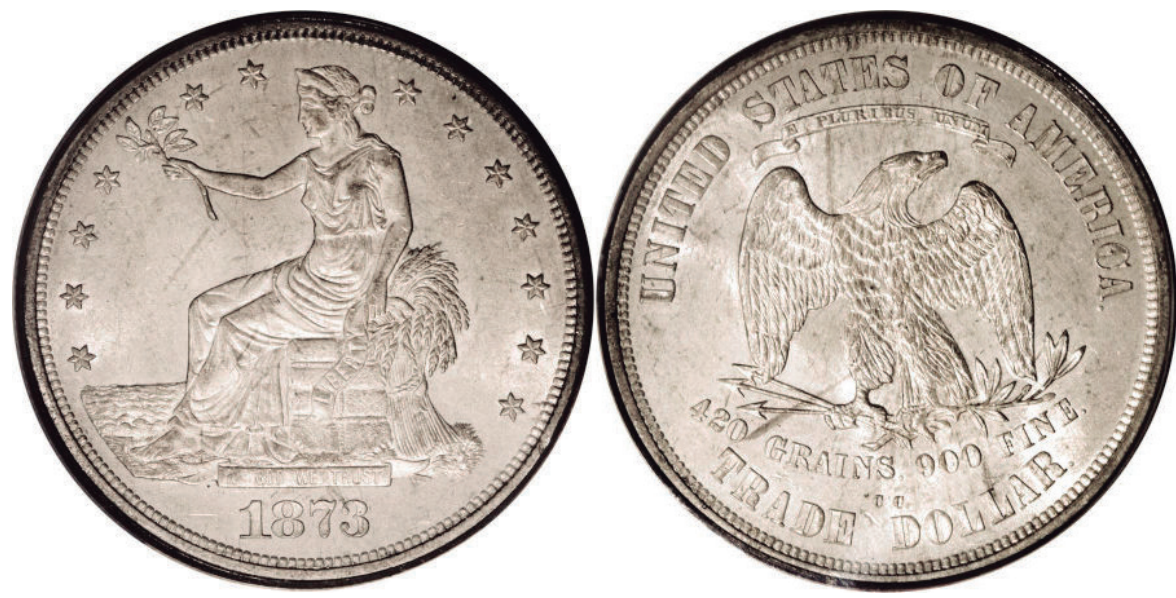

Fuente: CoinHELP (2018).

La emisión de los American Trade Dollars se vio favorecida por el descubrimiento de las minas de plata de Nevada. Su valor intrínseco era mayor que el del peso mexicano, dado que tenía 378 granos, y desde su emisión en 1871 se destinó al comercio exterior. La enorme cantidad de plata puesta en circulación hundió el mercado de la plata mundial, y unos ocho millones de ellos 
volvieron a Estados Unidos y fueron reacuñados y otros 28 millones fueron posiblemente fundidos por los chinos (McMaster, 1959, p. 392).

Otro importante competidor fue el propio yen japonés. El Gobierno japonés compró las prensas al Gobierno británico de Hong Kong y acuñó 165 millones de yenes entre 1871 y 1897, y de ellos por lo menos 110 millones se exportaron para competir con el peso mexicano en Asia. En 1873 el yen se devaluó respecto al dólar estadounidense, y unos años después, en 1897, su valor era de solamente 50 centavos de dólar. Este último año Japón se adhirió al patrón monetario del oro.

Estas monedas japonesas fueron muy populares en los mercados asiáticos, ya que su intrincado dibujo las hacía muy difíciles de falsificar, pero dejaron de circular cuando Japón utilizó la indemnización de su guerra con China en 1894 para adoptar el patrón oro (McMaster, 1959, p. 392). Tan pronto como en 1874 el yen de plata japonés tuvo curso legal en Singapur, pero era recibido por los comerciantes con un descuento de un $0.5-1.5 \%$ en relación con el peso mexicano. Por ello, en septiembre de 1879 el Gobierno japonés estableció que el yen debía ser aceptado en paridad con el peso. El yen era principalmente exportado a Singapur y a Hong Kong para equilibrar la deficitaria balanza comercial, y era una moneda muy común en la circulación de ambos puertos en 1890, con una estimación realizada por los cónsules de ocho millones en el primero de ellos y de medio millón en Hong Kong (Motoyama \& Yokoyama, 1994, p. 2).

Con las nuevas emisiones de la era Meiji se desmonetizó el circulante anterior, cayendo en desuso la antigua moneda de cobre. El antiguo monetario áureo y argénteo fue adquirido y fundido por el Banco Nacional de Japón, haciéndose en poco tiempo tan escasas las monedas que incluso los coleccionistas numismáticos japoneses de finales del siglo XIX tuvieron que recurrir a copias por falta de ejemplares originales (Seco, 2010, p. 172).

El epílogo del importante papel de los pesos mexicanos en los mercados asiáticos lo marcó el Partido Comunista Chino, que en mayo de 1928 emitió la primera moneda de la revolución socialista en China, una réplica casi exacta del peso mexicano o moneda del águila (Francioni, 2018). 


\section{Referencias bibliográficas}

Andrew, A. P. (1904). The End of the Mexican Dollar. The Quarterly Journal of Economics, 18(3), 321-356.

Angot, A. (marzo, abril y mayo, 1876). La Nueva Era en el Japón. Revista europea VII(7), 74-79.

Barrón, M. C. (1992). La Presencia novohispana en el Pacífico insular: actas de las Segundas Jornadas Internacionales celebradas en la ciudad de México, del 17 al 21 de septiembre de 1990. México: Universidad Iberoamericana.

Biblioteca Nacional de España, Madrid. (1858). Carta de España de Bachiller con todas sus posesiones de ultramar e islas adyacentes 1858, Fragmento: Islas Marianas, Palaos y Carolinas (Oceanía). Recuperado de http://www. bne.es/es/Busqueda/resultado.html?cx=008390202817838809661\%3A ezzszwraciu\&cof=FORID\%3A11\&searchdata1=\&text=\&advanced $=$ false \&field=todos\&sa. $x=45 \&$ sa. $y=14 \&$ exact $=$ on\&q=Carta + de + Espa\%C3\%B1 a+de+Bachiller+con+todas+sus+posesiones+de+ultramar+e+islas+adyac entes+1858\%2C+Fragmento\%3A+Islas+Marianas\%2C+Palaos+y+Caroli nas+\%28Ocean\%C3\%ADa\%29\&btnBuscar=

Bonialian, M. (2012). El Pacífico hispanoamericano: política y comercio asiático en el Imperio Español (1680-1784). México: El Colegio de México.

Cano, B. P. (2010). De las extraordinarias exportaciones de plata desde los países civilizados del mundo occidental hacia India y China. Folios $\mathrm{Nu}$ mismáticos, (50), 648-649.

Cano, B. P. (2016). La moneda circulante en la Capitanía General de Filipinas (siglos XVI al XVIII). México y la Cuenca del Pacífico, 15(5), 97-123.

Cano, B. P. (2018). El real de a ocho español y las primeras economías-mundo a finales del siglo XVIII. Oroinformación. Recuperado de https://oroinformacion.com/el-real-de-a-ocho-espanol-y-las-primeras-economiasmundo-a-finales-del-siglo-xviii/

Chalmers, R. (1893). A History of currency in the British Colonies. Londres, Reino Unido: H.M. Stationery Off., by Eyre and Spottiswoode.

Cipolla, C. M. (1996). La Odisea de la plata española: Conquistadores, piratas y mercaderes. Barcelona, España: Crítica.

CoinHELP. (2018). American Trade Dollar de 1872. Recuperado de http:// coinauctionshelp.com/silverdollars/ 
Duport., S. C. (1843). De la production des Métaux Précieux au Mexique, Considérée dans ses rapports avec la géologie, la métallurgie et l'économie politique. Paris, Francia: Firmin Didot Fréres.

Eckfeldt J. R., \& Du Bois W. E. (1842). A manual of gold and silver coins of all nations. Filadelfia, Estados Unidos de América: Assay Office of the Mint.

Elizalde P. M. (2004). Restar en vez de sumar. La política seguida en Filipinas desde la perspectiva de dos fines de siglo. En Vega, S.E., (ed.) Jirones de Hispanidad. España, Cuba, Puerto Rico y Filipinas en la perspectiva de dos cambios de siglo (pp. 359-377). Salamanca, España: Universidad de Salamanca.

Flynn, D. O., \& Giráldez, A. (2000). Imperial monetary policy in global perspective. En Bernal, A.M., (ed.), Dinero, moneda y crédito en la Monarquía Hispánica (pp. 385-404). Madrid, España: Marcial Pons.

Francioni, A. (junio, 2018). The Pacific World in a silver grain. The Imperial Maritime Customs Service, the 'Eagle coin' and China-Mexico connections in the XIX century: notes on currency, imperialism and good governance. Università degli studi di Siena, Italy.

Gaceta de Madrid año CCX. (31 de enero de 1871). Tratado de amistad, comercio y navegación (Núm. 35).

Gunder Frank, A. (1998). ReOrient: Global Economy in the Asian Age. Estados Unidos de América: University of California Press.

Iaccarino, U. (2013). El papel del Galeón de Manila en el Japón de Tokugawa Ierasu. En Salvador B., A. \& Martínez S., C. (Eds.) Un océano de seda y plata: el universo económico del Galeón de Manila, (pp. 133-153). Sevilla España: EEHA/CSIC.

Library of Congress Geography and Map Division Washington, D.C. (1881). Mapa de China y Japón en 1881 G7820. Recuperado de https://www.loc. gov/rr/geogmap/

Martínez T. G. (2015). Comercio intra-asiático y dinámicas inter-imperiales en Asia oriental: el Japón Meiji y las colonias asiáticas del imperio español. Millars: Espai i Història, (39), 125-157.

MA-SHOPS (2018). Yen de oro del año 3 de la Era Meiji, 1871. Recuperado de https://www.ma-shops.com/kohlross/

McMaster, J. (1959). Aventuras asiáticas del peso mexicano. Historia Mexicana, 3(8), 372-399.

Motoyama Y. \& Yokoyama S. (1994). The Japanese Currency Policy and the British Banks in Asia in 1870s-1890s. The Kyoto University Economic Review. Memoirs of the Faculty of Economics, LXIV(1), 1-8. 
Seco S. I. (2010). Historia breve de Japón. Madrid, España: Sílex Ediciones. Shopify Coins (2018). Un yen de plata del año 3 de la Era Meiji. Recuperado de https://mmrarecoins.myshopify.com/products/

Te K'un, C. (1961). A brief history of Chinese silver currency. Selections from the Numismatist, American Numismatic Association, 55(11), 781-788.

Tratado de amistad, comercio y navegación ajustado entre España y el Japón y firmado en Kanagawa. (12 de noviembre de 1868). Documentos internacionales que corresponden a la época intermedia de los Gobiernos constituidos desde el mes de octubre de 1868 hasta fin del año 1874: colección oficial publicada por el Ministerio de Estado con los datos auténticos de su archivo. Madrid, España: Imprenta de Miguel Ginesta.

Valdés L. V. (noviembre, 2003). El peso mexicano en el Este de Asia después del siglo XVIII. XI Congreso Internacional de ALADAA. México. Recuperado de http://ceaa.colmex.mx/aladaa/imagesmemoria/veravaldes.pdf

VCoins The Online Coin Show. (2018). Peso mexicano de 1870. Recuperado de https://www.vcoins.com/en/Search.aspx?search=true\&searchQuery=pes o+1870\&searchQueryExclude=\&searchCategory=0\&searchCategoryLevel $=2 \&$ searchCategoryAncient=True\&searchCategoryUs=True\&searchCateg oryWorld=True\&searchCategoryMedieval=False\&searchBetween $=0 \&$ sear chBetweenAnd=0\&searchDate $=\&$ searchUseThesaurus=True\&searchDispl ayCurrency $=\&$ searchDisplay $=1 \&$ searchIdStore $=0 \&$ searchQueryAnyWord $s=\&$ searchExactPhrase $=\&$ searchTitleAndDescription $=$ True\&searchDateT ype $=0 \&$ searchMaxRecords $=100 \&$ SearchOnSale $=$ False $\&$ Unassigned $=$ False 